\title{
Study on the effect of cetyltrimethylammonium bromide on gas-liquid flow characteristics at low gas flow rates and gas pressure
}

\author{
A. Yu. Yushkov ${ }^{1}$, V. A. Ogai ${ }^{1}$, I.A. Koroleva ${ }^{1}$, Moh'd M. Amro ${ }^{2}$, Frederick Rose ${ }^{2}$, Nicolai- \\ Alexeji Kummer ${ }^{2}$ \\ ${ }^{1}$ Industrial University of Tyumen, Department of Development and Operation of Oil and Gas Fields, \\ Institute of Geology and Oil and Gas Production, Tyumen, Russia \\ ${ }^{2}$ TU Bergakademie Freiberg, Institute of Drilling Engineering and Fluid Mining, Freiberg, Germany
}

\begin{abstract}
Cenomanian gas deposits account for about $80 \%$ of natural gas production in Russia. Today, mature Cenomanian gas fields are depleted by more than $75 \%$ on average, the reservoir pressure in the productive formation zone has decreased by almost $90 \%$ compared to the initial pressure and in some places reaches 1.0-1.5 MPa. Reduction of pressure in the pay zone leads to active intrusion of water from the aquifer. The liquid is loading the well, and gas production decreases. The technology of gas well operation with foaming agent is widespread in the world, which is characterized by a high level of efficiency, including economic. The use of technology leads to a solution to the liquid loading and requires a preliminary selection of the optimal concentration of surfactants. The optimal concentration should ensure the creation of a relatively stable foam and provide a minimum pressure gradient in the production tubing. The article presents the results of studies of CTAB foaming agent influence on the process of liquid removal and pressure gradient in production tubing. Sequential studies to determine CMC, foamability, foam stability, and pressure gradient under foam flow were conducted on small-scale and large-scale facilities. These results can be reliable when using CTAB foaming agent, foaming agents based on it, or other cationic foaming agents in Cenomanian gas wells under the condition of reservoir water inflow. Besides, the effect of pressure on the optimal concentration of the foaming agent was also studied in this work.
\end{abstract}

\section{Introduction}

The major natural gas fields in Western Siberia (Russia) are part of the Aptian-Cenomanian gas-prone complex [1]. The complex contains about two-thirds of natural gas proved reserves in Western Siberia. Cenomanian gas deposits account for about $80 \%$ of natural gas production in Russia. Gas reservoirs are sandstones and siltstones with variable amounts of clay admixture. The existing deposits are up to $1300 \mathrm{~m}$ in depth and are in contact with an active aquifer, and the geological structure and the main geological and geophysical characteristics are identical: pay zone thickness can reach $250 \mathrm{~m}$, average porosity is 30 - 
$37 \%$, permeability varies from 0.001 to $7 \mu \mathrm{m}^{2}$, gas saturation from $47 \%$ to $93 \%$. Cenomanian gas contains about $98 \%$ methane.

Unique deposits of Cenomanian gas, such as Medvezhye, Urengoy, Yamburg, and others are mature fields. Today, these deposits are depleted on average by more than $75 \%$, reservoir pressure in the pay zone has decreased by almost $90 \%$ from the initial one, and in some places reaches 1.0-1.5 MPa. Reduction of pressure in the reservoir's pay zone leads to the active intrusion of water from the aquifer. For example, at the Medvezhye gas field, when $80 \%$ of the initial reserves were withdrawn, $35-38 \%$ of the initial gas-saturated volume was flooded [2].

Most Cenomanian gas fields are characterized by problems that complicate gas production, such as average daily gas production rates decreased by 4-5 times compared to the initial ones, which leads to the accumulation of liquid at the bottom and in the production tubing; continuous purging is required to clean the wellbore and prevent well shutdown. Such wells make up for more than $20 \%$ of the total well stock, each year their number increases [3]. This problem is one of the most essential in the Cenomanian gas production and world gas production. For its solution, special studies are carried out $[4,5$, $6,7]$ and various technologies are used, such as compression, velocity tubing, plunger lift, gas lift, rod pump, electric centrifugal pump, etc. $[8,9,10,11,12]$. The generalized analysis of the experience of using various deliquification technologies in several thousand wells [13] shows that the use of foaming agent injection technology requires the lowest capital investment (up to $\$ 10,000$ ) and provides a good increase in gas production (up to 9,360 Mcf/well·year). The comparison of the technologies is presented in Table 1.

Table 1. The comparison of the deliquification technologies.

\begin{tabular}{lcccc}
\hline & $\begin{array}{c}\text { Use } \\
\text { Foaming } \\
\text { Agents }\end{array}$ & $\begin{array}{c}\text { Install } \\
\text { Velocity } \\
\text { Tubing }\end{array}$ & $\begin{array}{c}\text { "Smart”Well } \\
\text { Automated } \\
\text { Controls for } \\
\text { Plunger Lift }\end{array}$ & $\begin{array}{c}\text { Install Rod } \\
\text { Pumps and } \\
\text { Pumping } \\
\text { Units }\end{array}$ \\
\hline $\begin{array}{c}\text { The volume of Natural Gas } \\
\text { Savings and Incremental } \\
\text { Production, Mcf/well/year }\end{array}$ & $500-9,360$ & $9,285-27,610$ & $800-1,463$ & $973-2,040$ \\
\hline Implementation Cost, \$/well & $500-9,880$ & $7000-64,000$ & $5,700-18,000$ & $\begin{array}{c}41,000- \\
62,000\end{array}$ \\
\hline
\end{tabular}

Analysis of other literature sources also confirms the high efficiency of using foaming agents $[14,15,16,17,18]$. Surfactants can be introduced into the well as solid sticks or as liquid solutions. With proper selection of the composition [19], surfactants can be used to remove water (condensation and formation) and gas condensate from both vertical and horizontal wells, at different pressures and temperatures (including high) [20, 21, 22]. There is a successful experience in the application the capillary foam deliquification technology in horizontal wells with middle-shallow depth, low pressures, and low liquid flow rates [23]. The technology principle is to inject the foaming agent into the bottom hole of the well using a plunger pump and a capillary string installed into the well. In the Russian Federation, considerable experience of application surfactant in various regions is accumulated: on fields of the North Caucasus, Krasnodar Krai, the Orenburg Region, the Far North (Yamburg, Urengoy, Medvezhye, etc.).

The deliquification of gas wells at the inlet of the foaming agent is due to its interaction with the fluid and the ascending gas flow, which leads to the appearance of foam, a decrease in the density of the gas-liquid mixture and a decrease in the surface tension of the liquid and gas. As a result, fluid removal's critical gas velocity is reduced. 
Gas well operation technology with foaming agent requires preliminary selection of optimal surfactant concentration. The optimal concentration should ensure the creation of relatively stable foam. However, there is an increase in the interfacial friction between the gas and the film of viscous foam with an increase in surfactant concentration (Fig. 1), which leads to an increase of the pressure gradient [24]. Thus, it is necessary to choose the concentration of foaming agent, which provides a minimum pressure gradient in the production tubing. This is the most advantageous case from an economic and technological perspective.

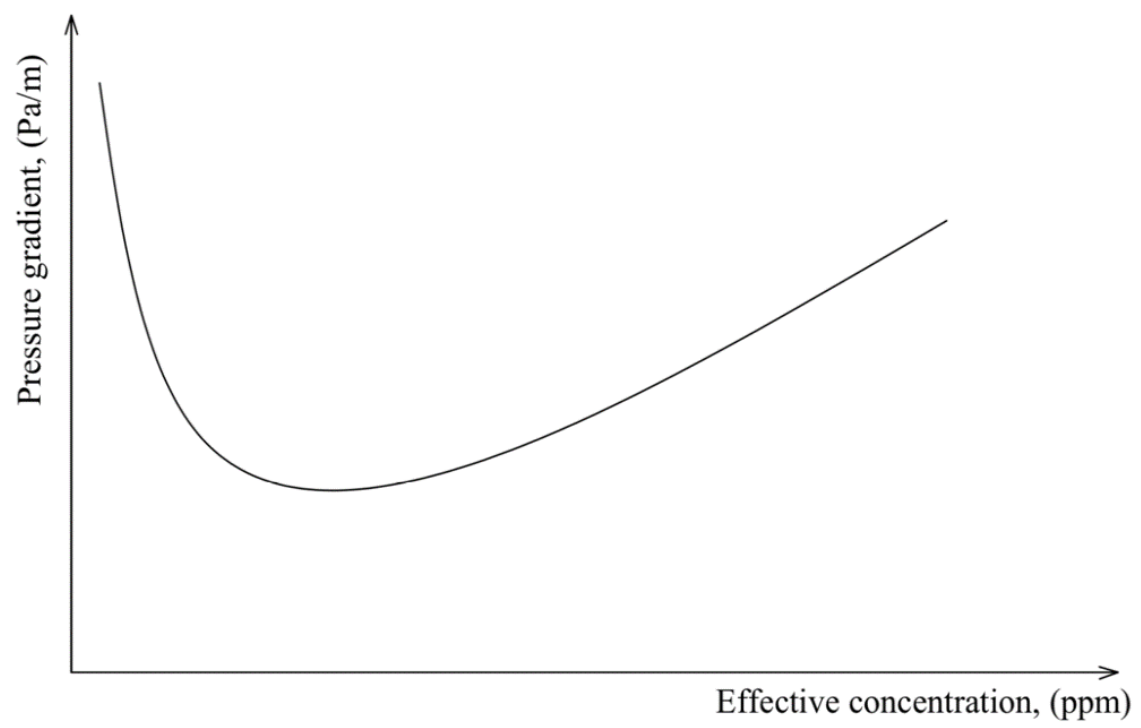

Fig. 1. Schematic dependence of the pressure gradient on the effective surfactant concentration.

\section{Study subject and research methods}

As part of these two-way studies of the effect of foaming agent on the process of liquid removal from Cenomanian gas wells, the cationic foaming agent CTAB (cetyltrimethylammonium bromid, $\mathrm{C}_{19} \mathrm{H}_{42} \mathrm{BrN}$ ) was selected. This foaming agent provides foamability of water solutions with high salt content [30].

Cationic surfactants in aqueous solutions dissociate into a surface-active cation and anion. When the foaming agent is added to the liquid solution, the surface tension is reduced, which facilitates gas dispersion in the liquid phase. From a practical point of view, when choosing a product to use, good indicators are the ease of foamability, the high foam half-life of the foam, and the percentage of mass unloaded in different media at different temperatures with the exception of deionized water [25].

The ionic composition of aquifer waters is relatively similar in various Cenomanian gas fields. The results of the component composition analysis of reservoir and condensate fluids taken from the Urengoy field, which were received during the systematic monitoring and hydrochemical analysis of well fluid samples, were taken as a basis [31]. The compositions of the prepared simulated solutions are presented in Table 2.

Table 2. Chemical compositions of test solutions.

$$
\mathrm{Cl}^{-}, \mathrm{g} / \mathrm{l} \quad \mathrm{HCO}^{-}, \mathrm{g} / \mathrm{l} \quad \mathrm{Na}^{+}, \mathrm{g} / 1 \quad \mathrm{Mg}^{2+}, \mathrm{g} / \mathrm{l} \quad \mathrm{Ca}^{2+}, \mathrm{g} / 1
$$




\begin{tabular}{lccccc}
\hline $\begin{array}{l}\text { Formation water } \\
\rho=1.1 \mathrm{~g} / \mathrm{cm}^{3}\end{array}$ & 11.003 & 0.242 & 6.683 & 0.1 & 0.272 \\
$\begin{array}{l}\text { Condensation water } \\
\rho=0.998 \mathrm{~g} / \mathrm{cm}^{3}\end{array}$ & 0.218 & 0.117 & 0.141 & - & 0.038 \\
\hline
\end{tabular}

Before conducting tests on the large-scale facilities to determine the conditions of removal of liquid and the pressure drop, it is customary to determine the properties of the surfactant understudy and critical micelle's concentration. The CCM is the concentration at which the surface tension value is minimal. Reducing the surface tension facilitates the dispersion of the solution with gas and increases the foamability of the solution.

The test to determine the surface tension of the solutions was carried out on the installation KRÜSS Force Tensiometer - K11 (ring method) in TU Bergakademie Freiberg (Institute of Drilling Engineering and Fluid Mining). The test solution is placed into an experimental chamber, where a drop is formed. The camera captures the drop profile, which is processed using the software. It defines the drop contour, calculates the radius of curvature at its vertex, and compares experimental drop contours with theoretical ones to derive the surface tension value.

Then tests are performed to determine the foamability of the solutions and stability of the foam by shear mixing in a measuring cylinder [26, 27]. The tests are performed sequentially. The test solution of $100 \mathrm{ml}$ with a certain concentration of surfactant is placed in a measuring cylinder and whipped for one minute at a mixer blade speed of $1560 \mathrm{rpm}$. After stopping the mixer, we determine the initial volume of liquid in the foam. This test is very important for determining the preliminary surfactant concentration for formed stable foam flow in the well. Next, we determine the half-life of the foam, that is, the time required to recover $50 \%$ of the volume of the initial solution from the foam structure. The experiments were conducted at TU Bergakademie Freiberg (Institute of Drilling Engineering and Fluid Mining).

The tests on a large-scale facility using CTAB foaming agent to determine the conditions for removing the liquid and the pressure gradient in a production tubing were carried out at the Industrial University of Tyumen. Experimental work was conducted on a specially designed large-scale facility (experimental bench, a patent for an invention in the Russian Federation No. 265889). The bench management and control of flow parameters are carried out using specially developed software (certificate of registration of the computer program in the Russian Federation No. 265889). The functional scheme and technical specifications of the facility are shown in Figure 2 and Table 3.

Table 3. Technical specifications of the facility.

\begin{tabular}{lll}
\hline Specification & Unit & Value \\
\hline Production tubing length (basic)* & 6 & $\mathrm{~m}$ \\
Outer / inner diameter of tubing (basic)* & 42 & $\mathrm{~mm}$ \\
Working pressure in the system (not more than) & 1.5 & $\mathrm{MPa}$ \\
Working range of temperature (not more than) & 50 & ${ }^{\circ} \mathrm{C}$ \\
Max superficial gas velocity at pressure 1.5 MPa ** & 15 & $\mathrm{~m} / \mathrm{s}$
\end{tabular}


*It is possible to change the diameter of the tubing and the tubing length.

**For the base diameter of

tubing.

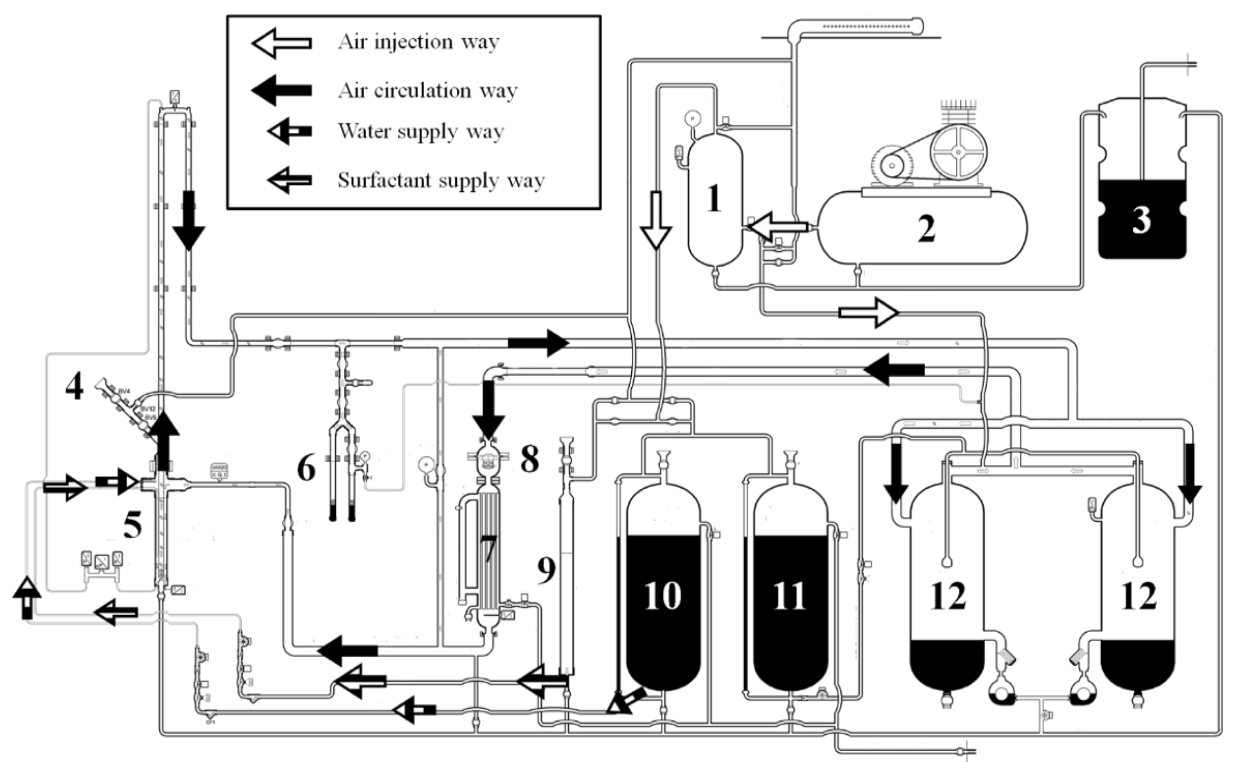

Fig. 2. Schematic diagram of the experimental stand. 1 - air receiver; 2 - compressor; 3 - disposal tank; 4 - the unit of injection the solid surfactant; 5 - production tubing; 6 - foam sampling unit; 7 temperature control unit; 8 - centrifugal air pump; 9 - the unit of injection the liquid surfactant; 10 the unit of injection the water (de-ionized water/ brine solution); 11 - tank with water for defoaming; 12 - tanks for defoaming.

Before starting the experiment, the operator panel was used to set the experiment parameters: pressure and temperature of the experiment in the production tubing. When the appropriate experimental pressure is reached, it is maintained by injecting air using a compressor and then monitoring the pressure using pressure sensors and opening / closing the solenoid valves for air injection. The temperature control unit ensures that the appropriate temperature of the circulating air and the liquid supplied to the production tubing are maintained. The required gas flow rate is set by automatically adjusting the power of the centrifugal air pump, thus maintaining the required speed of rotation of the blades. Before entering the production tubing, the gas passes through the air pump and then the airflow meter. This way, the specified gas flow rate is reached and maintained for a certain period. The supply of liquid with the required concentration of foaming agent to the downhole of the production tubing is carried out under the influence of pressure gradient between the unit of injection of water (the liquid surfactant) and the downhole of the tube. The pressure gradient value is selected using software for the appropriate flow rate of the liquid. The liquid passes through the turbine flow meters before being injected into the production tubing. Thus, gas and liquid separately, but simultaneously enter the downhole, pass through the disperser of liquid and gas, foam is formed and the mixture rises along the production tube due to the pressure. After the mixture passes through the tube, it flows down the reverse current pipe through the pipe binder and enters the tanks for defoaming and settling the foam, where the liquid is separated from the gas. Then the gas circulates and enters the inlet of the ccentrifugal air pump (repeating the cycle of gas circulation), and 
the liquid from the foam with the help of steam traps enters the disposal tank. Additional (relatively large) amount of water is pumped into the foam tanks causing a sharp decrease in the concentration of surfactants, and the foam disintegration accelerates. After the start of injection of the liquid to the downhole, when the foam rises to the top of the lift column, it is maintained for 5 minutes to stabilize the flow. Flow stabilization is observed both visually by means of video fixation and by means of flow parameter indications on the operator panel tab. The flow rate of liquid and gas and the pressure gradient value are stabilized. The pressure gradient, the main measured value, is measured using a pressure sensor that records the difference in pressure values between the top and bottom of the production tubing.

The tests were conducted with the following parameters: the temperature and pressure in the production tubing $\mathrm{t}=30-32{ }^{0} \mathrm{C}, \mathrm{P}=10 \mathrm{bar}$, the liquid flow rate $\mathrm{Q}_{l}=3 \mathrm{l} / \mathrm{min}$, gas velocity $\mathrm{V}_{\mathrm{g}}=4 \mathrm{~m} / \mathrm{s}$ under conditions close to the conditions of Cenomanian gas production at the final stage of development when reservoir water breaks into the well. Formation water (brine solution) was taken as test solutions (Table 1).

The choice of the gas flow velocity value was made based on Tochigin and Turner's equations, which are common in evaluating the critical velocity in Cenomanian gas wells. The problem of liquid accumulation at the bottom of the well occurs due to depletion of reservoir energy, which reduces the flow velocity below the critical velocity. The critical velocity value is the minimum required velocity for carrying the liquid to the surface. In this article, we have considered two approaches to determining the critical velocity: according to Turner's equation (Formula 1) [28] and Tochigin's equation (Formula 2) [33].

$$
\begin{gathered}
u_{t}=\left[\frac{40\left(\rho_{l}-\rho_{g}\right) \gamma g}{\rho_{g}^{2} C_{D}}\right]^{\frac{1}{4}} \\
u \geq 3,3 \cdot \sqrt[4]{\frac{\sigma g \rho_{l}^{2}}{\left(\rho_{l}-\rho_{g}\right) \cdot \rho_{g}^{2}}}
\end{gathered}
$$

where $\mathrm{p}_{1}=$ liquid density, $(\mathrm{g} / \mathrm{m} 3) ; \mathrm{p}_{\mathrm{g}}=$ gas density, $(\mathrm{g} / \mathrm{m} 3) ; \mathrm{C}_{\mathrm{D}}=$ frontal collision coefficient; $\dot{\mathrm{G}}=$ surface tension $(\mathrm{N} / \mathrm{m})$.

We obtained critical velocity values of $4.8 \mathrm{~m} / \mathrm{s}$ using Turner's equation and $5.2 \mathrm{~m} / \mathrm{s}$ using Tochigin's equation for our conditions. Based on the data obtained, We chose a flow velocity of $4 \mathrm{~m} / \mathrm{s}$ for subsequent tests based on data obtained.

\section{Results}

The obtained results for determining the CCM for test solutions are shown in Figure 3. For a simulated solution of condensation Cenomanian water, the CMC was $305 \mathrm{ppm}$, and for a simulated solution of formation Cenomanian water, $10 \mathrm{ppm}$. The obtained results are consistent with the results of the research of H.Nakahara [29] and B.Petkova [30], which also showed a decrease in $\mathrm{CMC}$ with the addition of salts $(\mathrm{NaCl})$ to the solution. The effect is most pronounced in solutions with a high concentration of salts. The tests were repeated 5 times for each measurement, with a standard deviation of $0.1 \mathrm{mN} / \mathrm{m}$.

The results of the solution foamability and stability of the foam tests are shown in Figure 4 and Figure 5. The tests were repeated 5 times for each measurement. In experiments with a simulated solution of condensation Cenomanian water, at a concentration close to CCM (10 ppm), the amount of liquid in the foam was very small, so it was decided to gradually increase the concentration of surfactants. An increase in the foamed liquid volume leads to an increase in the surface area between the liquid and the gas, which requires more foaming 
agent molecules [32]. Therefore, with an increase in the foaming agent concentration, a greater amount of stable foam is formed. In the solution with high salt content, with an increase in the foaming agent concentration, its deviation from the CMC and the half-life of the foam decreases.

(a)

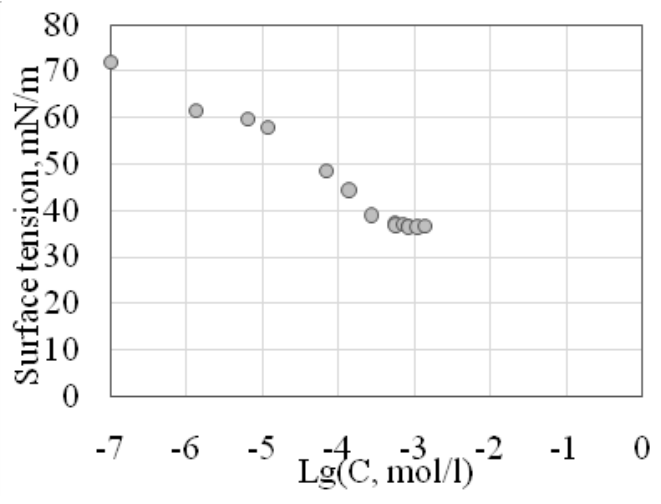

(b)

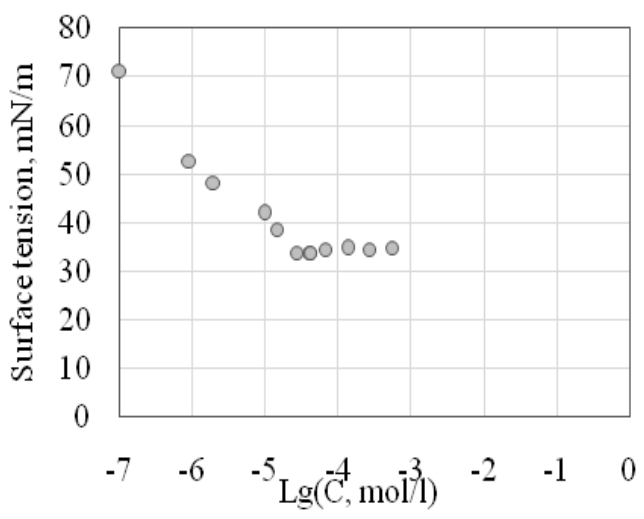

Fig. 3. Equilibrium surface tension as a function of CTAB concentration. The simulated solution of (a) condensation water (b) formation water.

(a)

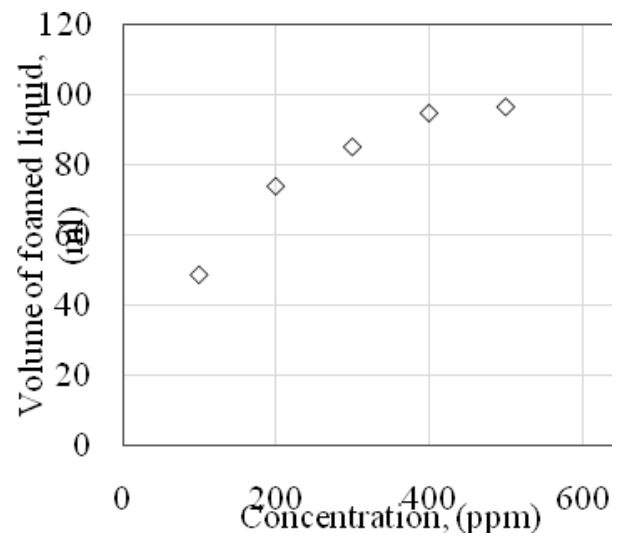

(b)

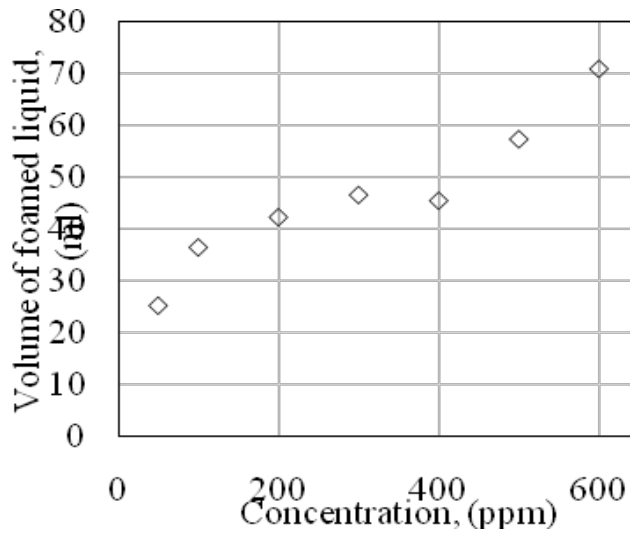

Fig. 4. Volume of foamed liquid as a function of CTAB concentration. The simulated solution of (a) condensation water (b) formation water.
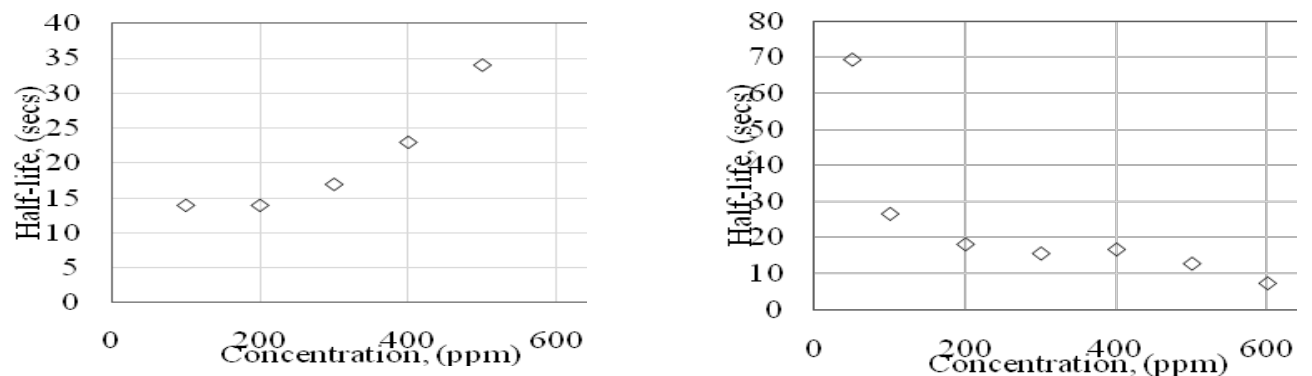

Fig. 5. The half-life of the foam as a function of $\mathrm{CTAB}$ concentration. The simulated solution of (a) condensation water (b) formation water. 
Based on the results of the small-scale tests with the brine solution (foam ability and stability of the foam), the foaming agent concentrations were selected for experiments on a large-scale facility. The foaming agent concentration was gradually increased to achieve the optimal value, which corresponds to the pressure gradient minimum. The results are shown in Figure 6. Based on the results of the experiments, it was found that at the CTAB concentration up to $1000 \mathrm{ppm}$, there is an accumulation of liquid in the production tubing. At a foaming agent concentration of $1000 \mathrm{ppm}$ or more, a stable annular flow is observed without liquid loading. Addition of CTAB surfactant in the solution allowed to reduce the value of the calculated critical velocity of the mixture defined by Turner's equation and Tochigin's equation. The minimum pressure gradient was observed at a concentration close to $1500 \mathrm{ppm}$.

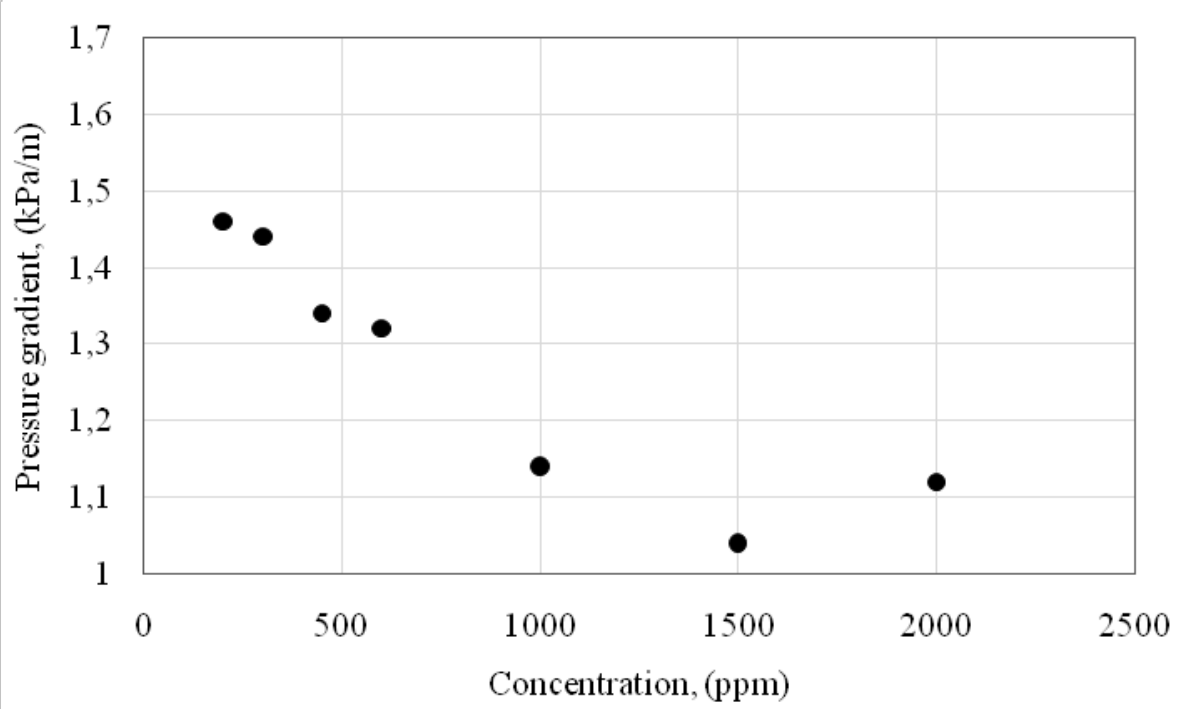

Fig. 6. Pressure gradient as a function of $\mathrm{CTAB}$ concentration at $\mathrm{t}=30-32{ }^{0} \mathrm{C}, \mathrm{P}=10$ bar, $\mathrm{V}_{\mathrm{g}}=4$ $\mathrm{m} / \mathrm{sec}, \mathrm{Q}_{l}=31 / \mathrm{min}, \mathrm{d}=0,042 \mathrm{~m}$. 


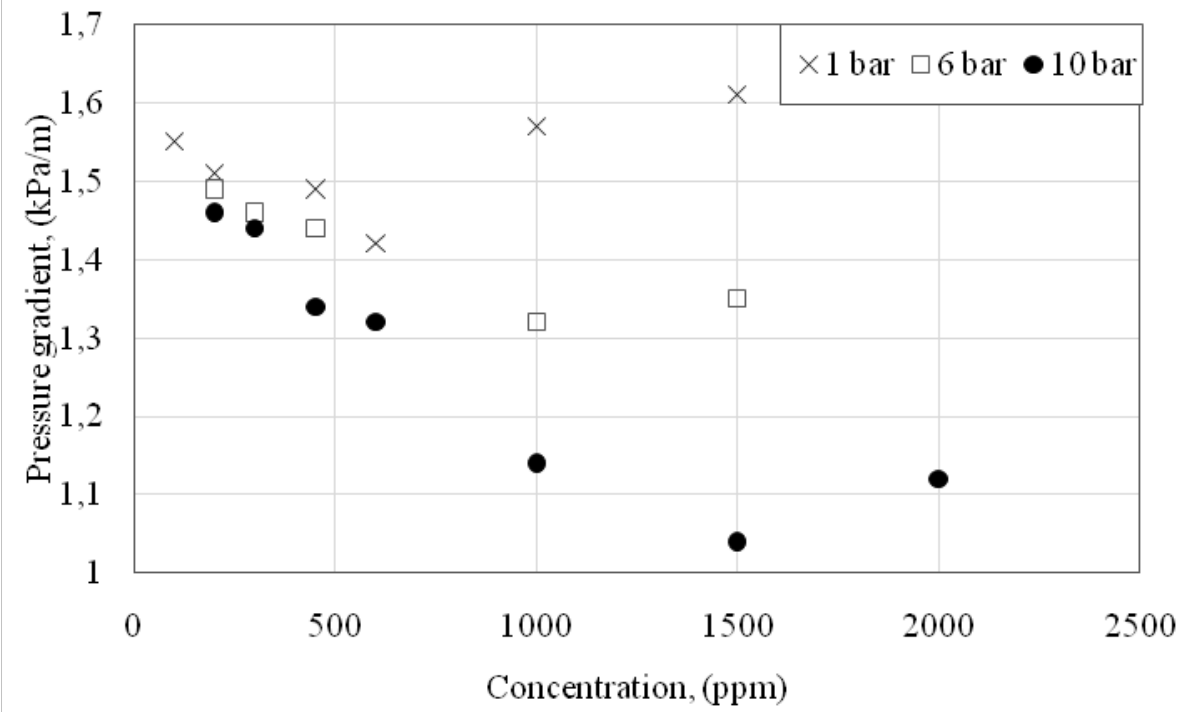

Fig. 7. Pressure gradient as a function of $\mathrm{CTAB}$ concentration at $\mathrm{t}=30-32{ }^{0} \mathrm{C}, \mathrm{V}_{\mathrm{g}}=4 \mathrm{~m} / \mathrm{sec}, \mathrm{Q}_{l}=3$ $1 / \mathrm{min}, \mathrm{d}=0,042 \mathrm{~m}$.

The influence of pressure on the foaming agent optimal concentration was also studied in this work. The obtained data are of some interest and scientific novelty. In the course of the literature analysis, no experimental studies on a large-scale facility at various pressure values were found [34]. The results are shown in Figure 7. With an increase in pressure, there is an increase in the value of the optimal concentration of the foaming agent at which the minimum pressure gradient is reached. In atmospheric pressure conditions, the optimal concentration value is close to $600 \mathrm{ppm}$, and at $10 \mathrm{bar}$, to $1500 \mathrm{ppm}$. The increase in the pressure gradient at a relatively high concentration of foaming agent is associated with the formation of a large amount of foam, which leads to an increase of interfacial friction between the gas and the film [35]. The formed foam is more stable and contains more liquid when the pressure increases [36]. It is possible that the foam formed at a higher pressure takes a smaller volume in the tubing at the same concentration of the foaming agent, and also has a higher ability to carry the liquid out of the tubing. This is due to a shift in the optimal concentration of the foaming agent towards higher concentrations, as well as a decrease in the pressure gradient when the pressure increases, as the liquid content in the flow decreases.

\section{Conclusions}

The results of studies of the effect of CTAB foam on the parameters of gas-liquid flow at a relatively high flow rate of saline solution showed that for thermo baric conditions close to the operation of gas wells in the Cenomanian mature fields (pressure 10 bar and temperature $30-32^{\circ} \mathrm{C}$ ) with adding a foaming agent at a concentration of $1000 \mathrm{ppm}$ and above causes a decrease of the critical speed and provides for obtaining a stable annular flow without the liquid loading. At the same time, the optimal concentration of the foaming agent with a minimum pressure gradient is about $1500 \mathrm{ppm}$. These results can be useful when using CTAB foaming agent, foaming agents based on it, or other cationic foaming agents in Cenomanian gas wells under the condition of reservoir water inflow. In particular, the use of the obtained data allows choosing the foaming agent optimal concentration. This allows reducing costs by eliminating excessive consumption of surfactants. Also, achieving 
the minimum pressure gradient in the tubing at the foaming agent optimal concentration minimizes the bottom-hole pressure and increases gas production.

\section{References}

1. O. Andreyev, K. Basniev, L. Berman, Features of exploration and development of gas deposits in Western Siberia. (Nedra, 1984).

2. P.S. Kolmakov, A.V. Krotov, Kononov. Technologies for developing Cenomanian deposits oflow-pressure gas. (Nedra, 2012).

3. V.Z. Minlikaev, A.V. Kovalenko, N.A. Bilalov, A.V. Elistratov, Results of the implementation of Comprehensive program on the reconstruction and technical reequipment of gas recovery facilities for 2011-2015. Gas Industry 1(747): 30-34 (2017).

4. J. Zhu, G. Cao, W. Tian, Q. Zhao, H. Zhu, J. Song, J. Peng, Z. Lin, H.-Q. Zhang, Improved Data Mining for Production Diagnosis of Gas Wells with Plunger Lift through Dynamic Simulations. SPE Annual Technical Conference and Exhibition held in Calgary, Alberta, Canada (2019).

5. Sh. Shi, X. Wu, G. Han, Z. Zhong, Study on the gas-liquid annular vortex flow for liquid unloading of gas well. Oil \& Gas Science and Technology - Rev. IFP Energies nouvelles 74, 82 (2019).

6. H. Dallagi, Ah. Al. Saabi, Ch. Faille, Th. Benezech, W. \& Aloui, F. Augustin, CFD Simultions of the Rheological Behavior of Aqueous Foam Flow Through a HalfSudden Expansion. $8^{\text {th }}$ Joint Fluids Engineering Conference (2019).

7. P. Amania, S. Hurterbc, V. Rudolpha, M. Firouzi, Comparison of flow dynamics of air-water flows with foam flows in vertical pipes. Experimental Thermal and Fluid Science, 119 (2020).

8. E. Khamehchi, M. Khishvand, H. Abdolhosseini, A case study to an optimum selection of d liquification method for gas condensate well design: South Pars gas field. Ain Shams Engineering Journal, 7(2): 847-853 (2016).

9. H. Saradva, S. Jain, M.A. Hamadi, K.K. Thakur, G. Govindan, A.F. Ahmed, Evaluating Liquid Loading Using Multiphase Dynamic Flow Simulation in Complex Openhole Multilateral Gas Condensate Wells. SPE Middle East Oil and Gas Show and Conference. (2019).

10. M. Burns, Plunger-Assisted Gas Lift and Gas-Assisted Plunger Lift. SPE Artificial Lift Conference and Exhibition - Americas. (2018).

11. M.C. Romer, M. Brown, N. Ainsworth, O. Rundberg, D.J. Bolt, T. Bolt, R.C. Tolman, Field Trial of a Novel Self-Reciprocating Hydraulic Pump for Deliquification. SPE North America Atificial Lift Conference and Exhibition. (2016).

12. J. Burford, G. Falcone, Deliquification in a Mature Gas Field: Comparison of Predicted and Oserved Rates after Well Workover to Install Velocity Strings. SPE Latin America and Caribbean Petrleum Engineering Conference. (2017).

13. Natural Gas STAR Partners. Options for Removing Accumulated Fluid and Improving Flow in Gas Wells. (United States Environmental Protection Agency Air and Radiation, 2011).

14. A.Y. Koryakin, Complex solutions of problems of development and operation of wells of the Urengoy producing complex. (M. 2016). 
15. S.A. Kalwar, A.Q. Awan, A.U. Rehman, H.S. Abbasi, Production Optimization of High Temperature Liquid Hold-Up Gas Well Using Capillary Surfactant Injection. SPE Middle East Oil \& Gas Show and Conference. (2017).

16. O. Rauf, Gas Well Deliquification-A Brief Comparison between Foam Squeeze and Foam Batch Approach. Journal of Industrial and Intelligent Information, 3(1): 45-47 (2015).

17. H.P. Sean, L.N. Shona, C. Krevor, Investigation of Batch Foamer Efficacy and Optimisation in North Sea Gas Condensate Wells. (SPE Candidate Paper. 2013).

18. W. Schinagl, M. Caskie, S.R. Green, M. Docherty, A.C. Hodds, Most Successful Batch Aplication of Surfactant in North Sea Gas Wells. (Offshore Europe, 2007).

19. F. Huang, D. Nguyen, Optimized foamers for natural gas well deliquification: a statistical d sign approach. Fuel 97: 523-530 (2012).

20. Y. Alzhanov, H. Karami, E. Pereyra, J. Gamboa, Efficacy of Surfactants in Rich Gas Shale Wells. SPE Artificial Lift Conference and Exhibition-Amercas. (2018)

21. C. Gcali, H. Karami, E. Pereyra, C. Sarica, Surfactant Batch Treatment Efficiency as an Atificial Lift Method for Horizontal Gas Wells. SPE Artificial Lift Conference and Exhibition-Amercas. (2018).

22. P.S. Omrani, R.K. Shukla, F. Vercauteren, E. Nennie, Towards a Better Selection of Foamers for the Deliquification of Mature Gas Wells. International Petroleum Technology Conference. (2016).

23. T. Liu, X. Zhou, H. Chen, G. Lu, Zh. Zhao, D. Liu, Y. Du, Popularization and application of the capillary foam deliquification technology in horizontal wells with low pressures and low liquid flow rates: A case study on middle shallow gas reservoirs in the Western Sichuan depression. Natural Gas Industry B, 6, 25-33 (2019).

24. M. Kelkar, C. Sarica, Gas Well Pressure Drop Prediction under Foam Flow Conditions. (RPSEA 09122-01 Final Report, 2015).

25. N. Politova, S. Tcholakova, Z. Valkova, K. Golemanov, N.D. Denkov, Self-regulation of foam volume and bubble size during foaming via shear mixing. Colloids Surfaces: Physicochem. Eng. Asp.2018; 539: 18-28 (2018).

26. M.V. Turitsyna, A review of the results of research on solutions of surfactants and gasliquid mixtures based on them. Modern problems of science and education 2: 271, (2012).

27. R. Turner, M. Hubbard, A. Dukler, Analysis and prediction of minimum flow rate for the co tinuous removal of liquids from gas wells. Journal of Petroleum 22 (11), 14751482 (1969).

28. H. Nakahara, O. Shibata, Y. Moroi, Examination of Surface Adsorpshion of Cetyltrim thylammonium Bromide and Sodium Dodecyl Sulfate. J. Phys. Chem. B, 115: 90779086 (2011).

29. B. Petkova, S. Tcholakova, M. Chenkova, K. Golemanov, N. Denkov, D. Thorley, S. Stoyanov, Foamability of aqueous solutions: Role of surfactant type and concentration, Advances in colloid and interface science, 276, 102084 (2019).

30. A.V. Koshelev, G.S. Li, M.A. Kataeva, Operational hydrochemical control of reservoir water flooding of Urengoy oil and gas condensate field development facilities. Scientific and technical colection. Vesti Gazovoy Nauki, 3(19): 106-115. (2014).

31. G.E. Odishariya, A.A. Tochigin, Applied hydrodynamics of gas-liquid mixtures. (VNIIGAZ, 1998). 
32. M. Szabries, P.T. Jaeger, M.M. Amro, Foam analysis at elevated pressures for EOR applictions. Energy \& Fuels 33(5): 3743-3752 (2018).

33. W. Karnanda, M.S. Benzagouta, A. AlQuraishi, M. M. Amro, Effect of temperature, pressure,salinity, and surfactant concentration on IFT for surfactant flooding optimization. Arabian Journal of Geosciences, 6(9), 3535-3544 (2013).

34. J.M.C. Van't Westende, R.A.W.M. Henkes, A. Ajani, M. Kelkar, The use of surfactants for gas well deliquification: a comparison of research projects and developed models. (BHR Group, 2017).

35. A.T. Van Nimwegen, L.M. Portela, R.A.W.M. Henkes, Modeling of upwards gasliquid annular and churn flow with surfactants in vertical pipes. International Journal of Multiphase Flow: 105, 1-14 (2018)

36. S. Joshi, Foamer evaluation by the sparging test method for application to gas well deliquifiction. The dissertation on competition of a scientific degree of Cand. Tech. Sci. (Delft University of Technology, 2015). 